\title{
Transport phenomenon of a vapour bubble attached to a downward surface
}

\author{
X.F. Peng a*, Y.J. Huang ${ }^{a}$, D.J. Lee ${ }^{b}$ \\ a Department of Thermal Engineering, Tsinghua University, Beijing 100084, People's Republic of China \\ ${ }^{b}$ Department of Chemical Engineering, Taiwan University, Taipei 106, People's Republic of China
}

(Received 2 May 2000, accepted 23 November 2000)

\begin{abstract}
The boiling characteristics of subcooled liquids on a heating surface facing downward were investigated experimentally. A jet flow observed to emerge from the bubble top was induced by interfacial evaporation and condensation rather than by natural convection due to buoyancy or by Marangoni flow due to surface tension gradients according to the work of Christopher et al. [14, 15]. The jet flow greatly enhanced the nucleate boiling heat transfer efficiency and is probably one of the most important intrinsic mechanisms in nucleate boiling. The heating surface temperature changes as the jet flow formed and dissipated in an oscillatory manner. The development of the thermal boundary layer and the surface temperature were also depressed by the jet flow. The liquid subcooling markedly affected the strength of the jet flow. The visual observations also indicated the existence of three different heat transfer modes at different heating levels: the single-phase liquid heat transfer mode governed by heat conduction with increasing thermal boundary layer thickness as the heat flux increased; the jet-flow boiling mode which is characterized by that the thermal boundary layer thickness is independent of the applied heat flux; and the fully-developed nucleate boiling mode. (C) 2001 Éditions scientifiques et médicales Elsevier SAS
\end{abstract}

boiling / jet flow / phase change / heat transfer / thermal boundary layer / bubble

\section{Nomenclature}

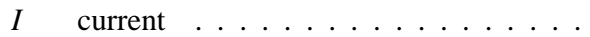

$L \quad$ length of heater . . . . . . . .

$P$ pressure ............

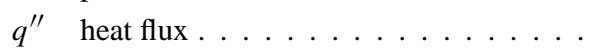

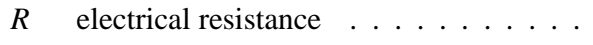

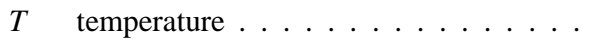

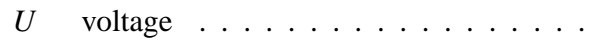

$W \quad$ width of heater

\section{Subscript}

f fluid or liquid

s saturation

sub subcooling

sup superheat

w wall

\footnotetext{
* Correspondance and reprints.

E-mail addresses: pxf-dte@mail.tsinghua.edu.cn (X.F. Peng), djlee@ccms.ntu.edu.tw (D.J. Lee).
}

\section{INTRODUCTION}

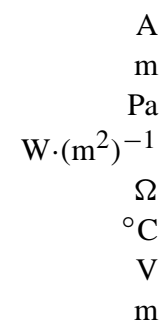

A

$\mathrm{m}$

$\mathrm{Pa}$

$\Omega$

${ }^{\circ} \mathrm{C}$

$\mathrm{V}$

$\mathrm{m}$
Despite numerous publications available in the open literature considering boiling heat transfer and the associated transport processes, many problems remain that are the subject of much debate. Various heat transfer mechanisms had been previously proposed to explain the high heat transfer efficiency observed in nucleate boiling. These mechanisms include buoyancy-induced macroconvection, the micro-convection caused by the bubble growth and departure, the microwedge layer evaporation, and the liquid-vapour mass and heat exchange [1-10]. Recently, Marangoni flow and the associated effects which are induced by surface tension gradients along the vapour-liquid interface of bubbles has been noted to be as strong as the previously proposed mechanisms in some special cases, such as in a microgravity environment where natural convection has no effect [11-15]. These investigations have provided a unique way to understand the intrinsic nature of the boiling process without the interference of earth gravity. 
Frost and Kippenhan [8] indicated that the energy transport caused by the mass exchange at the bubble interface, the evaporation at the bottom and the condensation at the top of the vapour bubble, accounts for most of the boiling heat transfer, especially for subcooled liquid boiling and for convective boiling. The numerical simulations of Christopher et al. $[14,15]$ showed that the liquid flow around a vapour bubble on the heated surface was mainly driven by the evaporation and condensation at the interface rather than by the Marangoni flow. The contribution of the Marangoni convection to the heat transfer rate was not significant. Existing experimental and theoretical evidence demonstrates that the interfacial heat transfer in a vapour bubble and the associated fluid flow dominates the heat transfer, particularly in the low heat flux nucleate boiling mode. However, a thorough understanding of the true nature of the nucleate boiling heat transfer process is still largely lacking.

This investigation mainly focuses on the interfacial phenomena of single vapour bubble, especially explore some experimental evidences which are independent upon gravitational force and other factors. For this purpose the experiments were conducted for downward surfaces, which is different from many available researches conducted to investigate the effect of surface orientation on boiling process [17-19]. This present paper presents an experimental investigation conducted to analyze the interfacial transport phenomena, the so-called "jet zone" that accompanies vapour bubbles. The thermal boundary layer thickness and the surface temperature were also measured. The results were used to identify the various boiling mode regimes.

\section{EXPERIMENT}

Figure 1 illustrates the experimental system set up for the present investigation, including a liquid vessel, test module, HP data acquisition system, CCD camera, and computer. The bottom plate was manufactured as a mini heat exchanger that serves as the cooler to maintain the temperature of the working liquid in the vessel. The MatoxMeter system (image analyzer, inserted in the computer) was employed as the photo acquisition system for image processing. A helium-neon laser was employed as light source for visual observation and image measurement. A pressure gauge was installed for pressure measurement with a thermocouple to measure the liquid temperature.

Figure 2 illustrates the test module arrangement. The cylindrical probe was made of cemented-wood that could sustain high temperature and served as an insulator. The boiling surface, a thin copper plate, $10 \mathrm{~mm} \times 6 \mathrm{~mm} \times$ $1 \mathrm{~mm}$, and a $6.03 \Omega$ heater were glued to the end of the cemented-wood probe. Due to installation problem the surface and heater were actually curved along the longitudinal direction, as it will be seen in figure 3 later. The heat was supplied by a DC power supply. The applied heat flux was determined by measuring the voltage drop across the heater. The boiling surface temperatures were measured by three thermocouples embedded on the back of the boiling plate.

The experiments used methanol and a water-methanol mixture with a mole fraction of $x=0.5$ as the working liquids. The boiling surface was faced downward to minimize the influence of gravity on the bubble dynamics.

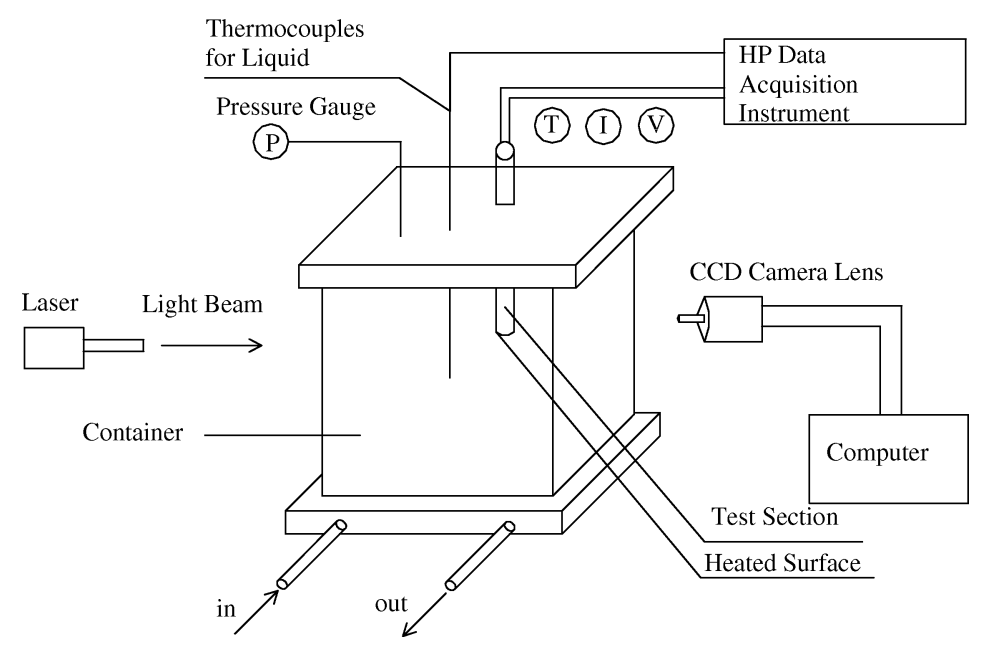

Figure 1. Experimental setup. 


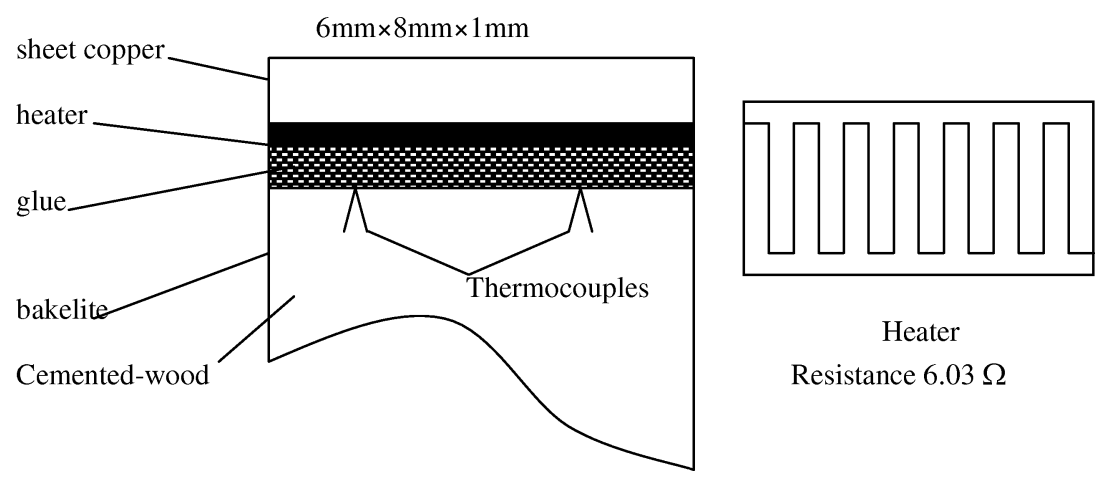

Figure 2. Test module.

Steady bubbles were, hence, easily formed and stayed on the heated surface for a sufficient time for observation. During the experiment the system was maintained at atmospheric pressure and the liquid temperature was less than the corresponding saturation temperature.

The boiling plate was thin, so the average of the three temperatures measured by the thermocouples on the back of the heater was used as the boiling surface temperature:

$$
T_{\mathrm{w}}=\frac{1}{N} \sum_{1}^{N} T_{i}
$$

The boiling heat flux was determined by:

$$
q^{\prime \prime}=\frac{U^{2}}{R L W}
$$

where $U$ denotes the voltage drop; and $R, L$, and $W$ are the electrical resistance, length, and width of the heater, respectively. The dynamic response of the thermal boundary layer was characterized through image analysis. The maximum uncertainty of the results was evaluated to be less than $8 \%$ [16].

\section{EXPERIMENTAL OBSERVATIONS}

Figure 3 illustrates several photographs of the methanol as it was heated at a bulk temperature of $19^{\circ} \mathrm{C}$, which is a subcooling of $45^{\circ} \mathrm{C}\left(\Delta T_{\text {sub }}=T_{\mathrm{s}}-T_{\mathrm{f}}=\right.$ $45^{\circ} \mathrm{C}$ ). Very clearly from figure $3(a)$, the liquid bulk remained quiet and stable with a lighter region near the heating surface which is the thermal boundary layer for low input voltage or heat flux. As figure 3(a) shows, the thermal boundary was about $2 \mathrm{~mm}$ in thickness at heat flux $q^{\prime \prime}=13.8 \mathrm{~kW} \cdot \mathrm{m}^{-2}$. As the input voltage was further increased, the surface temperature increased and the thermal boundary layer became wavy.

When the applied heat flux was about $31.1 \mathrm{~kW} \cdot \mathrm{m}^{-2}$ a small bubble formed in the thermal boundary layer. With the appearance of the bubble, a jet-like superheated liquid flow emerged from the bubble top and penetrated into the bulk liquid against the direction of gravity (figure 3(b)). The jet flow momentum was exhausted after travelling some distance from the bubble due to the resistance of the flow and of buoyancy. The bubble broke when its size grew up to larger than $3 \mathrm{~mm}$.

At still higher input power, $q^{\prime \prime}=55.3 \mathrm{~kW} \cdot \mathrm{m}^{-2}$ and $q^{\prime \prime}=86.4 \mathrm{~kW} \cdot \mathrm{m}^{-2}$, the bubbles grew larger in size. And the jet-like flow from the tops of the bubbles penetrated deeper into the bulk liquid than that at $q^{\prime \prime}=$ $31.1 \mathrm{~kW} \cdot \mathrm{m}^{-2}$ (figure $3(b)$ ), indicating a stronger jet flow with higher jet velocities. More bubbles, particularly smaller ones were generated on the heated surface, which induced more violent flow in the bulk liquid. Figure 3 (c) and $(d)$ illustrate such observations.

In saturated liquid boiling the jet flow behavior became almost invisible. Closer observation reveals that for saturation condition the bubbles were greater in size with the jet flow still produced from the region near the bubble top. The bulk liquid subcooling intensified the strength of the jet flow. At a very high liquid subcoolings, the bubbles decreased in size with very strong jet flow developing over most of the bubble interface. Therefore, more bulk liquid around the bubble was driven outwards from the heated surface, compared with the saturated boiling case. It is more obvious the jet flow phenomenon is highly dependent of the temperature difference. The thickness of thermal boundary layer was decreased a little bit rather 


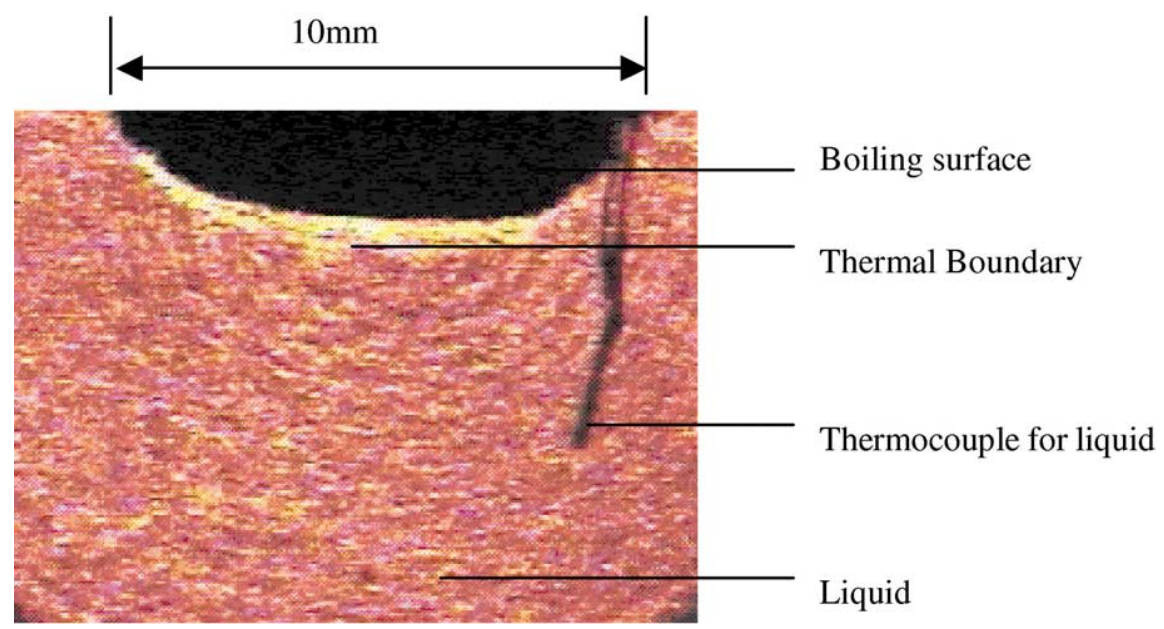

(a)

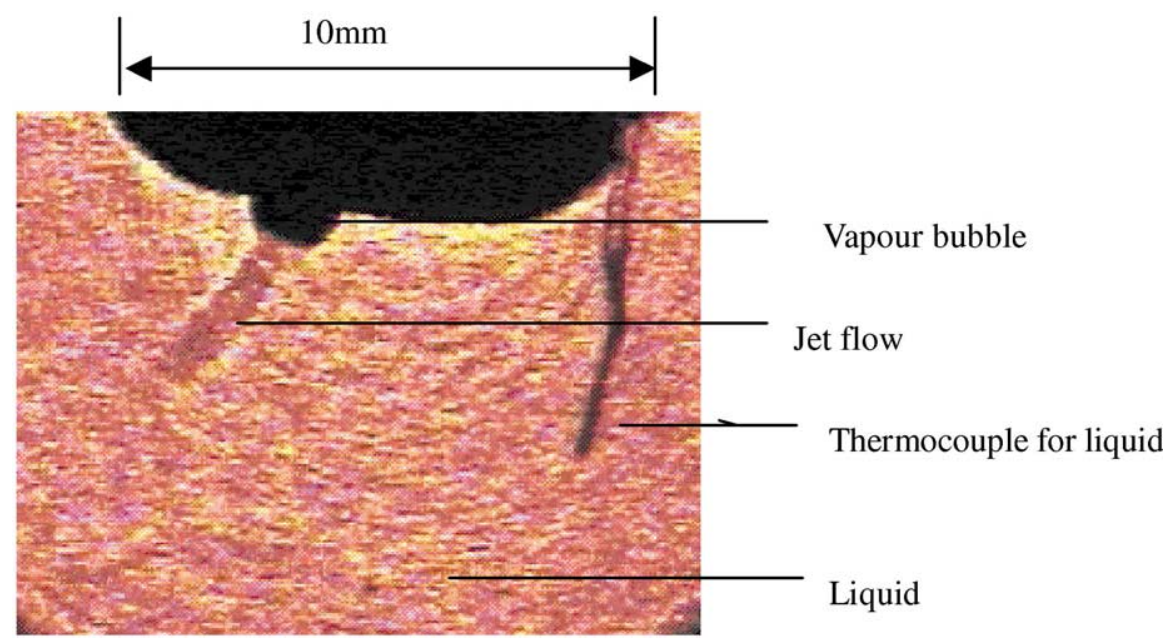

(b)

Figure 3. Jet flows emerging from the bubbles: (a) $q^{\prime \prime}=13.8 \mathrm{~kW} \cdot \mathrm{m}^{-2}$; (b) $q^{\prime \prime}=31.1 \mathrm{~kW} \cdot \mathrm{m}^{-2}$; (c) $q^{\prime \prime}=55.3 \mathrm{~kW} \cdot \mathrm{m}^{-2} ;$ (c) $q^{\prime \prime}=86.4 \mathrm{~kW} \cdot \mathrm{m}^{-2}$.

than increasing as bubble jet flow happened, as observed and compared the results in figure 3 . This means that the heat transfer should be enhanced by the jet flow. The results of water-methanol display very similar phenomena.

Therefore, the experimental observations suggest the following conclusions.

(1) The emergence of the jet flow can markedly enhance the heat transfer efficiency; therefore, the jets are an important heat transfer mechanism during boiling.
(2) The jet flow was not induced by natural convection or Marangoni flow, but was induced by evaporation and condensation at the bubble interface.

(3) The jet flow, the surface temperature, and the thermal boundary layer were highly interdependent. For example, the occurrence of the jet flow caused both the surface temperature and the thermal boundary layer thickness to decrease, especially in the region near the bubble.

(4) The liquid subcooling intensified the strength of the jet flow. 


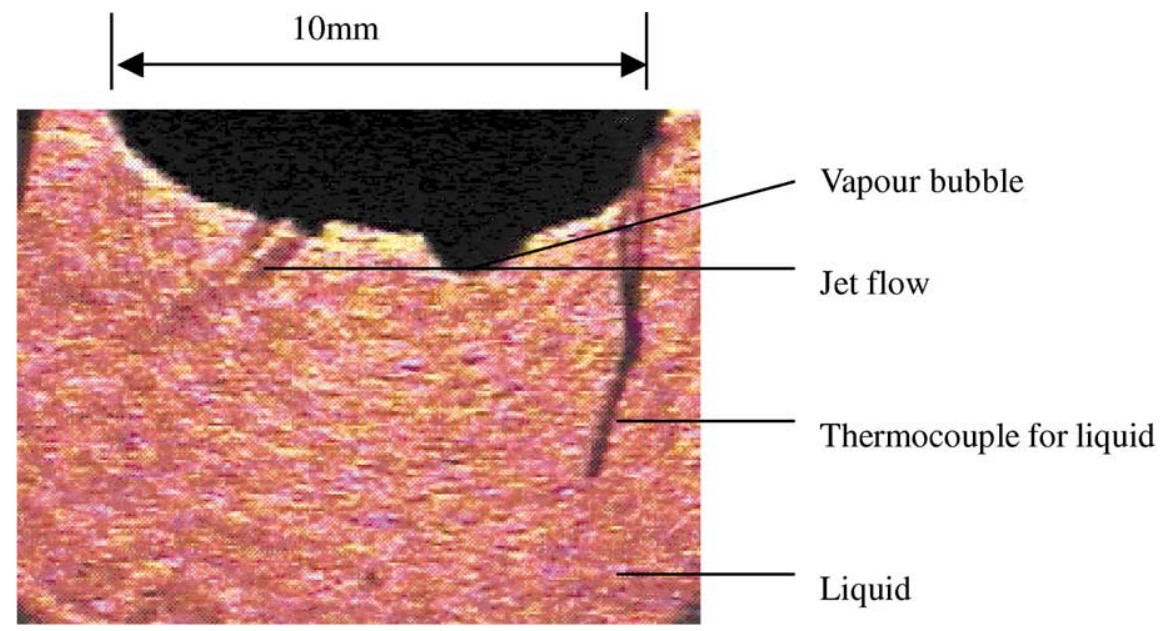

(c)

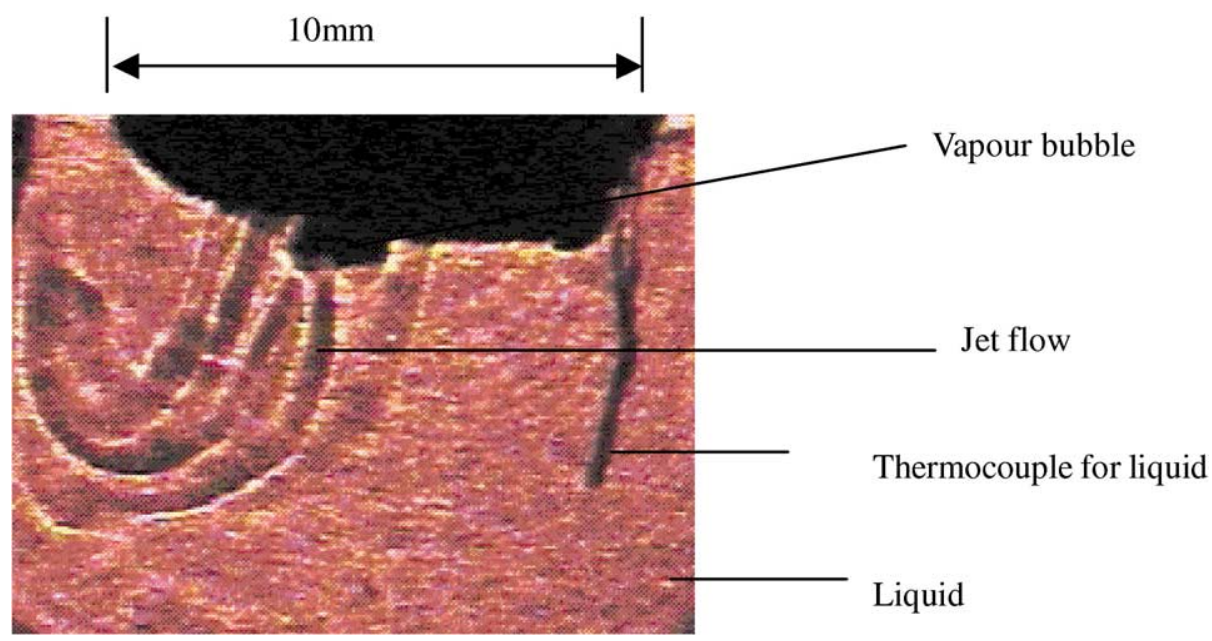

(d)

Figure 3. (continued).

\section{DISCUSSION}

In addition to the visual observations, the thermal boundary layer thickness and the surface temperature were measured during the experiments from image information by Matoxmeter system.

Figure 4 illustrates the thermal boundary layer thickness variation as a function of the applied heat flux. The thickness variation can be divided into three regimes. At a low heat flux the thickness increased with applied heat flux, indicating that the heat transfer mode in the liquid was basically heat conduction. At higher heat flux, the thermal boundary layer thickness surrounding the vapor bubble remained almost constant when the jet flow occurred, regardless of the applied heat flux. In some tests thermocouples embedded on the heated surface recorded a temperature drop of the surface that exceeded $10 \mathrm{~K}$ close to the bubbles during the jet mode as compared to the surrounding liquid further from the bubble. However, the thermal boundary layer thickness and the surface temperature rapidly recovered after bubble collapse. Obviously the heat transfer was dominated by the phasechange induced jet flow. The "pumping" action of the superheated liquid by the jet-like stream reduced the size of the thermal boundary layer and caused the liquid temper- 


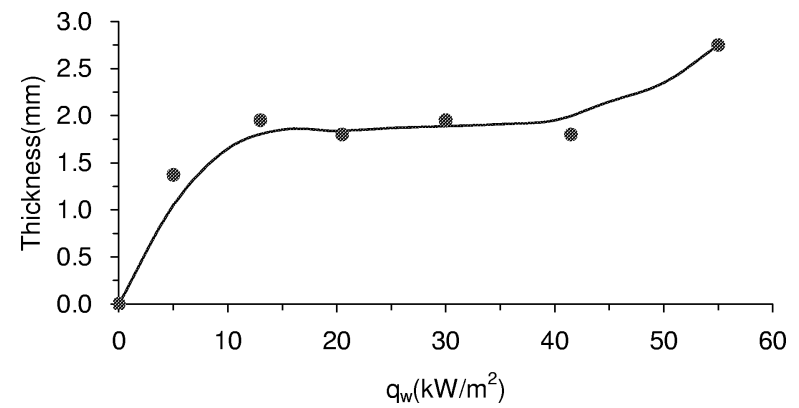

Figure 4. Effect of heat flux on the thermal boundary layer thickness.

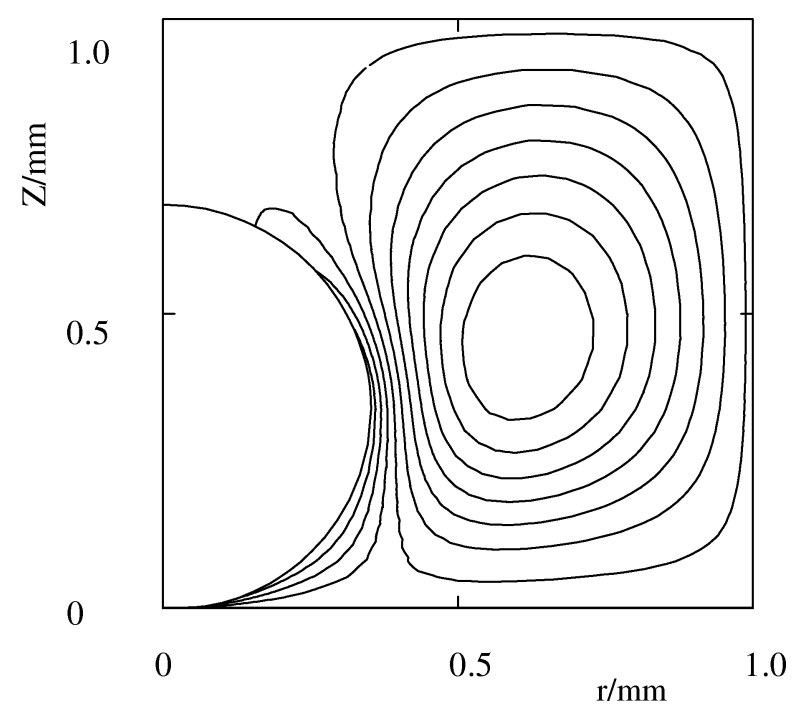

Figure 5. Numerically predicted stream function contours [15].

ature to decrease. We describe this regime as the "jet flow boiling" mode. At still higher heat fluxes, the nucleate boiling was fully developed. The jet flow could no longer efficiently expel a sufficient amount of superheated liquid so the thermal boundary layer thickness increased with applied heat flux.

The behavior of the thermal boundary layer provides strong support for the previously mentioned observations. Christopher et al. [15] investigated the liquid flow around a vapour bubble staying on a heated surface. The thermal boundary layer thickness was about the diameter of the bubble. The numerical simulations indicated that the flow field in the bulk liquid was mainly driven by the evaporation and condensation at the vapour bubble interface rather than by the buoyancy and the Marangoni flow. Figure 5 illustrates the typical stream function contours given by Christopher et al. [15]. The calculated flow field is quite similar to the experimentally observed flows in

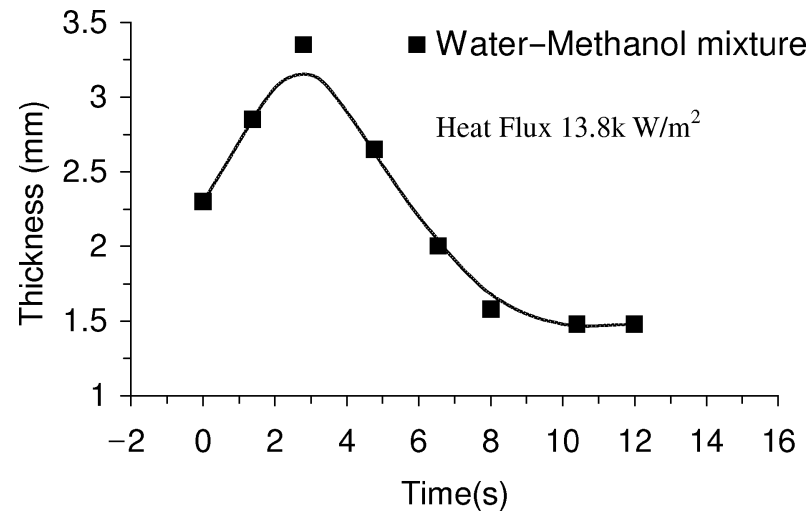

Figure 6. Change of thermal boundary layer thickness with time after power shut down (water-methanol mixture).

this investigation. The jet flow was apparent at the top of bubble in both the simulation and the experiments. The heat transfer calculation showed that most of the energy transfer occurred by vapor transport through the bubble. The vapor then condensed on the upper surface of the bubble and the energy was transferred to the bulk liquid region by the jet flow.

Figure 6 presents the change in the thermal boundary layer thickness with time when the applied power was suddenly turned off during steady-state nucleate boiling. The thermal boundary layer thickness first quickly increased rather than decreased with time until a maximum thickness was reached. Then the thickness decreased with time as is generally expected. The initial thickening of the boundary layer was quite surprising.

For the experiments conducted in this investigation, the heating surface faced downward. The bubbles and the heated liquid could not easily depart from the surface and a thermal boundary layer developed. The bubbles and the superheated liquid in the thermal boundary layer remained in place after the applied power was turned off. Then, since the bubbles could not be maintained without the heat supply, the bubbles collapsed, releasing a great amount of energy to heat the liquid in the thermal boundary layer and, hence, enlarge its thickness. Afterwards the thickness decreased as the energy dissipated to the bulk liquid. The heat could not be easily transferred from the surface and the thermal boundary layer without the jet flow. This analysis of the heat transfer mechanisms after the heating is terminated further demonstrates that the phase-change at the bubble surface and the associated jet flow are the mechanisms that are dominant for the boiling process. 


\section{CONCLUSIONS}

An experimental investigation was conducted to explore the development of a jet flow around a vapour bubble during boiling. For saturated boiling, the jet flow occurred at the bubble top. For subcooled conditions, the jet emerged from the vapour bubble around much of the bubble surface. This jet flow was induced by interfacial evaporation and condensation rather than by natural convection due to buoyancy or Marangoni flow due to surface tension gradients. The jet flow, as one of the most important intrinsic boiling mechanisms, greatly improves the nucleate boiling heat transfer rate by rapidly rejecting heat from the thermal boundary layer close to the heated surface. The surface temperature was also observed to vary dramatically as the jet formed. High liquid subcooling produced substantial jet flow from very small bubbles.

The measurement of the thermal boundary layer thickness revealed three distinct boiling modes: the singlephase liquid heat transfer mode governed by heat conduction, the jet flow boiling mode in which the thermal boundary layer is independent of the applied heat flux, and the fully-developed nucleate boiling mode. During the jet flow boiling mode, the heat transfer was mainly due to the effect of the jet flow.

\section{Acknowledgements}

This research was supported by the National Natural Science Foundation of China through contracts No. 59625612 and 59976016. DJL wishes to thank Tsinghua University for appointing him as a Visiting Professor during January to March, 2000. XFP wishes to thank National Taiwan University for appointing him as a Visiting Professor during February to August, 2000.

\section{REFERENCES}

[1] Forster H.K., Zuber N., Dynamics of vapor bubble and boiling heat transfer, AIChE J. 1 (1952) 531-535.

[2] Forster D.E., Greif R., Heat transfer to a boiling liquid-mechanism and correlation, J. Heat Transfer C 81 (1) (1959) 43-53.

[3] Han C.Y., Griffith P., The mechanism of heat transfer in nucleate pool boiling-Part I, Internat. J. Heat Mass Transfer 8 (1965) 887-904.
[4] Han C.Y., Griffith P., The mechanism of heat transfer in nucleate pool boiling-Part II, Internat. J. Heat Mass Transfer 8 (1965) 905-914.

[5] Moore F.D., Mesler R.B., The measurement of rapid surface temperature fluctuations during nucleate boiling, AIChE J. 7 (1961) 620-624.

[6] Van Stralen S.J.D., The mechanism of nucleate boiling in pure liquid and in binary mixtures-Part I, Internat. J. Heat Mass Transfer 9 (1966) 995-1020.

[7] Van Stralen S.J.D., The mechanism of nucleate boiling in pure liquid and in binary mixtures-Part II, Internat. J. Heat Mass Transfer 9 (1966) 1021-1046.

[8] Frost W., Kippenhan C.J., Bubble growth and heat transfer mechanism in the forced convection boiling of water containing a surface active agent, Internat. J. Heat Mass Transfer 10 (1967) 931-949.

[9] Dhir V.K., Nucleate and transition boiling heat transfer under pool and external flow conditions, Heat Transfer 1990 (1) (1990) 129-155.

[10] Carey V.P., Liquid-Vapor Phase Change Phenomena, Hemisphere, Washington, DC, 1992.

[1 1] Straub J., Transport phenomena in micro- and zerogravitational fields, in: Transport Phenomena Science and Technology 1992, Higher Education Press, Beijing, 1992, pp. 16-28.

[12] Straub J., The role of surface tension for twophase heat and mass transfer in the absence of gravity, Experimental Thermal and Fluid Science 9 (1994) 253-273.

[13] Straub J., Interfacial heat transfer in microgravity, in: Heat Transfer Science and Technology 1996, Higher Education Press, Beijing, 1996, pp. 11-28.

[14] Christopher D.M., Wang B.X., Peng X.F., Flow field around a condensing and evaporating vapor bubble in microgravity, in: Proc. Molecular and Microscale Heat Transfer in Material Processing and Other Applications, Part 2, 1996, pp. 162-170.

[15] Christopher D.M., Wang B.X., Peng X.F., Convection and evaporation in the microlayer under a vapor bubble in microgravity, in: Proc. $10^{\text {th }}$ International Symposium on Transport Phenomena in Thermal Science and Process Engineering, Kyoto, 1997, pp. 367-371.

[16] Huang Y.J., Investigation on boiling under microgravity, Ms. thesis, Tsinghua University, Beijing, 1999.

[17] Nishikawa K., Fujita Y., Uchida S., Ohta H., Effect of heating surface orientation on nucleate boiling, in: ASMEJSME Thermal Engng Joint Conf. Vol. 1, 1983, pp. 129-136.

[18] ElGenk M.S., A review of pool boiling from inclined and downward-facing flat surfaces, in: Celata G.P., Di Marco P., Mariani A. (Eds.), $2^{\text {nd }}$ European Thermal Science, 1996, pp. 1591-1600.

[19] Jung D.S., Venart J.E.S., Sousa A.C.M., Effects of enhanced surfaces and surface orientation and film boiling heat transfer in R-11, Internat. J. Heat Mass Transfer 30 (1987) 2627-2639. 